\title{
O Espelho e os Narcisos - A imagem do público entre os jornalistas goianos
}

\author{
The Mirror and the Daffodils - The image of the public \\ among journalists from Goiás
}

\author{
El espejo y los narcisos - La imagen del público \\ entre los periodistas goianos
}

José Eduardo Mendonça Umbelino ${ }^{1}$

Luiz Antônio Signates Freitas ${ }^{2}$

\begin{abstract}
Resumo
Uma vez que a comunicação midiática potencializa a indefinição do interlocutor e distancia os contextos daqueles que produzem e dos que consomem as informações, parte-se da premissa de que o jornalista precisa construir a imagem de quem o lê. Desse modo, foram entrevistados jornalistas dos dois principais jornais goianienses, com o intuito de aferir como eles tratam, definem e analisam seu público-leitor, e averiguar se existiria uma imagem de leitor compartilhada por todos, que independesse da empresa, das funções e da história pessoal de cada um dos entrevistados. A pesquisa demonstrou como é imprescindível analisar aquilo que os jornalistas pensam, e aquilo em que acreditam, para melhor compreender as bases do comportamento midiático na sociedade atual.
\end{abstract}

\begin{tabular}{|c|c|}
\hline & Acesse este artigo online \\
\hline \multirow{2}{*}{  } & $\begin{array}{l}\text { Website: } \\
\text { http://www.revistas.ufg.br/index.php/ci }\end{array}$ \\
\hline & $\begin{array}{l}\text { DOI: } \\
\text { http://dx.doi.org/10.5216/ci.v20i2.43063 }\end{array}$ \\
\hline
\end{tabular}

Palavras-chave: Estereótipo. Construção da realidade. Campo jornalístico.

Abstract
This research intends to study how
Goiânia's press journalists define, understand and describe their audience. As a primary goal, the researchers seek to ascertain whether there is a shared image of the reader, which would be different from those images provided by the newspaper companies, the common-sense or other instances. Knowing that Media increases vagueness and doubt about to "whom we speak to", we start from the premise that the journalists need to build up a picture of the audience. How they do it, based upon which cognitive subsidies, impressions or ideologies - that are relevant issues for this research.

Keywords: Stereotype. Reality construction. Journalistic field.

\section{Resumen}

${ }^{1}$ Doutorando em sociologia pela Universidade Federal de Goiás UFG. Tutor de Educação a Distância pelo Núcleo de Direitos Humanos (NDH) da UFG, para o curso de Especialização Interdisciplinar em Patrimônio, Direitos Culturais e Cidadania. E-mail: jeumbelino@gmail.com

2 Pós-Doutor em Epistemologia da Comunicação (Unisinos), Doutor em Ciências da Comunicação (USP). Professor associado I da Universidade Federal de Goiás, junto ao Mestrado em Comunicação, na linha Mídia e Cidadania e docente efetivo do Doutorado em Ciências da Religião, na linha Cultura e Sistemas Simbólicos, da Pontifícia Universidade Católica de Goiás. E-mail: signates@gmail.com

Comun. \& Inf., Goiânia, GO, v. 20, n. 2, p. 152-170, jul./out. 2017 
Una vez que la comunicación de los medios de comunicación aumenta la imprecisión del interlocutor y la distancia de los contextos de los que producen y los que consumen la información, se parte de la premisa de que el periodista tiene que construir una imagen de quien lo lee. Así eran periodistas de los dos principales periódicos goianienses entrevistados, con el fin de evaluar la forma en que tratan a definir y analizar el número de lectores, y averiguar si había una imagen de lector compartida por todo lo que independesse la empresa, funciones y historia personal de cada uno de los encuestados. La investigación ha demostrado que es esencial para analizar lo que los periodistas piensan y lo que creen, para entender mejor el comportamiento de los medios de bases en la sociedad actual.

Palabras clave: Estereotipo. La construcción de la realidad. Ámbito periodístico.

\section{INTRODUÇÃO}

presente artigo expõe os resultados de pesquisa empreendida pelo autor a
respeito da imagem do leitor construída pelos jornalistas. Os jornalistas
não só definem seus leitores por meio de imagens e estereótipos, como se relacionam com essas imagens às vezes mais intensamente do que com os próprios leitores. Moedas de troca, esteio de identidade, barganhas simbólicas, realidades vicárias, sósias e sidekicks, as imagens do leitor cumprem todos esses papéis e refletem em si os desencontros e as desavenças da profissão jornalística.

O público da mídia - ou seja, quem está do outro lado dos jornais, telejornais, revistas, etc. - representa uma das grandes questões dos estudos comunicacionais. Na verdade, sua condição indeterminada é premissa básica e constitutiva do próprio conceito atual de Comunicação. O comunicacional só se torna objeto de investigação quando transcende o comunicar-se face a face e passa a configurar uma circunstância de comunicação entre e para grupos, para multidões, para "massa", enfim, para o público. O princípio demarcador do conceito poderia ser resumido da seguinte forma: interessam as modalidades de comunicação nas quais aqueles que produzem conteúdo perderam, graças ao advento das tecnologias comunicacionais, a resposta imediata daqueles que consumiam.

O produto midiático, portanto, é produzido sob essa premissa; ele é arquitetado segundo a concepção de que atingirá todas as pessoas. Se isso ocorre de fato ou se é apenas uma das várias pretensões e sonhos de grandeza da mídia, não cabe a esse trabalho averiguar. Aqui interessa apenas que tal pressuposto firmou-se na mitologia social de modo tão profundo que é tido como um axioma básico. Desse modo, a indeterminação do público da mídia pode e será considerada apenas sob o prisma conceitual. Não se pretende aqui avaliar a acuidade com que a mídia descreve e mapeia seus públicos, e tampouco a constituição empírica e efetiva desse público, mas sim constatar que a Comunicação Mediada abre uma lacuna 
conceitual no lugar onde estaria o Outro para quem se fala. Tal lacuna não é necessariamente considerada uma falha, mas um resultado lógico de alguns atributos conferidos aos meios de comunicação atuais.

Quando o público está distante, as possibilidades interpretativas são múltiplas e a liberdade de comunicação é ampla. Diante desse quadro, a mídia se especializou internamente em confeccionar suas próprias realidades e em defendê-las. Em outras palavras, ela se vê no direito, ou na necessidade, de responder por conta própria a fatídica questão: quem está do outro lado? E de acreditar em suas próprias respostas.

\begin{abstract}
Por meio da interrupção do contato direto garante-se, por um lado, o alto grau de liberdade da comunicação. Com isso surge um excedente de possibilidades comunicacionais que só pode ser controlado dentro do sistema por meio da auto-organização e de reconstruções da realidade que lhe são próprias. (...) As organizações que produzem a comunicação dependem de suposições relativas a exigências desmedidas do público e da aceitabilidade das mesmas." (LUHMANN, 2005, p.17)
\end{abstract}

Portanto, o desafio do excesso de interpretações possíveis (oriundo da indeterminação do público) é vencido através da auto-organização e da legitimação das próprias suposições. A lacuna da Comunicação Midiática não permanece vaga, mas é ocupada pelo resultado de processos internos de explicação do mundo e de auto explicação. Sem o contato direto entre "emissor" e "receptor", as leituras paralelas e múltiplas tornam-se muito mais comuns, e a compreensão não encontra restrições objetivas por parte de quem produz a mensagem. É exatamente por isso que as instituições de comunicação precisam supor seus receptores, ou seja, precisam delimitá-los, reduzi-los, formatá-los. Caso contrário, teriam de trabalhar cotidianamente, e criar rotinas e padrões, a partir do caos de um público indefinível.

É difícil determinar o círculo de receptores para os meios de comunicação de massa (em comparação com a interação entre os presentes), receptores esses que estão atuando junto a cada momento. Em âmbito considerável, a presença inequívoca precisa ser substituída pela suposição dela. (LUHMANN, 2005, p. 19)

A mídia possui sua própria realidade interna, constituída pelos processos e operações que lhe dão conteúdo. Dentro dessa realidade interna, a imagem do público é mesmo uma incógnita, e Luhmann (2005) define como "incompetência" a incapacidade dos meios de terem certeza absoluta quanto a seus destinatários. Mas ele aponta um aspecto amenizador 
dessa incapacidade, que é o fato de que a Comunicação não é estática e pode, por tentativa e erro, descobrir quais métodos e mensagens atingem melhor seu público, refinando assim a imagem que tem dele.

Essa incompetência (para definir o público), contudo, tem a vantagem de não precisar tomar de forma muito restrita a curva recursiva da comunicação, e de que a comunicação, não se deixando bloquear imediatamente depois de fracassos ou contradições, possa buscar, pelo contrário, um público fiel e pode fazer experimentos com possibilidade de êxito. (LUHMANN, 2005, p.21)

Assim, ao longo de seu desenvolvimento, a mídia cria e aprimora mecanismos de redução das possibilidades interpretativas - tais como as pesquisas de público, os índices de audiência, a sistematização do estudo dos feedbacks colaterais, a intensificação dos canais de interatividade mediada ou direta, etc. Além disso, o próprio caminho dos meios de comunicação acompanha os desenlaces da sociedade e se torna funcional dentro de sua lógica, sendo passível de aferição e de auto-observação. A mídia reflete sobre si mesma e sobre a sociedade, e é capaz de observar seus erros e acertos. Ela não está dissociada dos outros elementos da sociedade e, mesmo se assim se imagina, não o faz de forma absoluta. Entretanto, levando-se em conta todas as relativizações prudentes e necessárias, ainda parece razoável manter a hipótese de que existe uma visão de mundo criada dentro da mídia e ela fornece imagens, estereótipos, arquétipos para suprir a lacuna da Comunicação. Diante da pluralidade atordoante de seu público, os jornalistas passam a escrever ou falar para simplificações desse público, ou seja, para estereótipos.

\section{ESTEREÓTIPOS}

Criamos estereótipos toda vez que interpretamos a realidade e, ainda que esses estereótipos sejam sempre simplificadores, rasos e valorativos, eles não necessariamente são sempre preconceituosos ou simplistas. Lippmann (2010) afirma que a mente humana não é capaz de abarcar a realidade de maneira integral e direta. Nas palavras de Dewey, o mundo complexo e desconhecido se apresentaria à percepção atônita dos homens como uma "grande, florida, ruidosa confusão" (DEWEY apud LIPPMANN, 2010, p. 84). O trabalho cognitivo de outorgar à realidade precisão, distinção, consistência e estabilidade é a base fundamental da formação de estereótipos. Eles são resultados de um processo interno de abordagem da realidade mas, diferente do tipo ideal weberiano, esse processo não necessariamente acontece 
de modo consciente ou direcionado. Enquanto o tipo ideal de Weber serve de suporte abstrato para que o cientista progrida no detalhamento da realidade, sem perder a noção da provisoriedade de seus modelos, os estereótipos correm sempre o risco de serem tomados como a própria realidade, e seu sucesso é tanto quanto for a comodidade que proporcionam a quem deles faz uso. Essa é uma distinção importante, uma vez que o conceito de estereótipo usado nesse trabalho guarda grande similaridade com o conceito de tipo ideal assim expresso por Weber:

Obtém-se um tipo ideal mediante a acentuação unilateral de um ou de vários pontos de vista e mediante o encadeamento de grande quantidade de fenômenos isoladamente dados, difusos e discretos, que se podem dar em maior ou menor número ou mesmo faltar por completo, e que se ordenam segundo os pontos de vista unilateralmente acentuados, a fim de se formar um quadro homogêneo de pensamento. É impossível encontrar empiricamente na realidade esse quadro, na sua pureza conceitual, pois tratase de uma utopia. (WEBER, 1993, p. 137)

Por seu lado, o estereótipo também intenta formar um "quadro homogêneo de pensamento", baseado na "acentuação unilateral de pontos de vista isolados" e num ordenamento segundo esses mesmos pontos de vista. Em outras palavras, o estereótipo se forma quando certas características de uma realidade específica são destacadas em relação às outras, para então serem reorganizadas entre si, recombinadas com outros aspectos muitas vezes não presente na realidade de origem, ressignificadas a partir desses aspectos e, finalmente, colocadas no lugar da realidade de onde surgiram. Assim como nos tipos ideais, nenhuma dessas ações cognitivas é feita de maneira neutra; a escolha das características não é arbitrária, as reorganizações não são ao léu, e o resultado final reflete as variações de cada etapa de sua construção.

O estereótipo é um construto abstrato que inexiste na realidade. Ele atende a uma operação de economia da mente pois, como diria Lippmann (2005), o exercício de abarcar todos os detalhes possíveis de uma maneira completamente original é exaustivo e em grande medida inútil. Não transitam pelas ruas do mundo príncipes totalmente encantados ou bruxas completamente malvadas, nem cariocas absolutamente malandros ou muçulmanos magistralmente terroristas, muito menos jornalistas absurdamente isentos que vivam romances terrivelmente fulminantes com políticos incrivelmente desonestos. Mas também é possível aferir que uma parte do estereótipo está sim na realidade. Essa parte representa a intersecção, a escolha econômica de elementos do real que comporão uma imagem. Ou seja, o

Comun. \& Inf., Goiânia, GO, v. 20, n. 2, p. 152-170, jul./out. 2017 
estereótipo não é um construto original e alienígena, confeccionado totalmente na mente e inserido onde é requisitado, mas um molde inspirado em traços gerais do real e é a escolha desses traços gerais, em detrimento de outros, que torna a formação de estereótipo um processo tão interessante. Essa escolha sim, atende a objetivos, intenções, desejos e suposição que podem não estar imediatamente no real.

Lippmann dirá ainda que o estereótipo prediz a realidade. Ele afirma: "Na maior parte dos casos nós não vemos em primeiro lugar, para então definir, nós definimos primeiro e então vemos." (LIPPMANN, 2010, p. 85). Essa afirmação não parece significar apenas que existe um sistema de referência ao qual o indivíduo recorre para entender o mundo, o que já foi dito anteriormente. O que Lippmann tenta expressar é que, na maioria das vezes, os indivíduos trabalham com os estereótipos já formados. Há, portanto, uma nova economia, dessa vez de etapas processuais, que gera novas condições. E isso se deve, segundo Lippmann, ao fato de que os homens vivem infinitas vezes as mesmas situações e não precisam ou não se dão ao trabalho de, em cada uma delas, realizar todo o processo de formação de estereótipo novamente. De modo que, na maioria das vezes, mais do que um trabalho de seleção de características e combinações, o que ocorre é um trabalho de seleção de estereótipos. Muitas vezes o elemento do real necessário para que o indivíduo chegue a um estereótipo é extremamente frágil e insignificante.

Uma vez criados e "empacotados", os estereótipos podem ser importados, exportados, comercializados e doados. Surge assim espaço para novas relações e valorações em um processo que transcende o âmbito individual e chega ao social ou coletivo. Se a formação de estereótipo em si poderia ser considerada um processo de cognição individual com intersecção no social, a evocação das realidades estereotipadas já se transforma num processo de negociação social com intersecção no individual. Em ambos os casos, o processo de negociação e formação de estereótipos se impregna na produção de discursos, textos e contextos em que vivem socialmente os indivíduos.

\section{IDENTIDADE E CAMPO SOCIAL}

O campo social do jornalismo constituiria uma fonte de valor simbólico e de imagens que justificariam o mundo e a presença dos jornalistas nele. Não se trata de uma estrutura altamente racionalizada e geral como os sistemas simbólicos de Bourdieu (2003), nem tampouco de uma união meramente afetiva e desprovida de objetivos claros como a socialidade orgânica de Maffesolli (2006). O campo social realiza uma simbiose desses

Comun. \& Inf., Goiânia, GO, v. 20, n. 2, p. 152-170, jul./out. 2017 
contextos para gerar um âmbito simbólico cuja escolha de inserção é mais consciente e cujo compartilhamento indica uma tomada ideológica de posição. Tanto é que ser jornalista, muito mais do que pertencer a uma identidade ou aceitar uma explicação de mundo, significa principalmente participar de uma luta, posicionar-se em defesa de valores desde sempre ameaçados. Assim, o campo social do jornalismo parece se construir diretamente sobre o confronto, e isso há de ser uma de suas maiores peculiaridades - aquilo que ele apresenta de mais firme é o mito da eterna rebeldia contra forças opressoras.

Os jornais eram vistos como um meio de exprimir as queixas e injustiças individuais e como uma forma de assegurar a proteção contra a tirania insensível. Portanto a legitimidade jornalística está na teoria democrática e, segundo os seus teóricos, assenta claramente numa postura de desconfiança (em relação ao poder) e numa cultura claramente adversarial entre jornalismo e poder. (TRAQUINA, 2005, p. 47)

Um campo social que funda sua mitologia na ideia de fazer frente ao poder dominante que não se reconhece como representante ou parte desse poder, mesmo que na prática o seja. Mas, se os jornalistas não se veem desse lado do jogo social, eles tampouco se consideram parte do outro lado; o jornalista também não é o público. Apesar de transitar nos mesmos espaços físicos e sociais, e mesmo que compartilhem vários sistemas simbólicos agregadores maiores (a nacionalidade, o conceito de cidadão, de morador urbano, etc.), pode-se observar que o jornalista não se considera e nem se vê como seu próprio público, não se confunde com ele, e não se reconhece nele. O público, portanto, também é um Outro para o jornalista. O fato é que muitos dos estudos sobre a cultura e o campo jornalísticos relativizaram ou minimizaram a importância do público no processo de confecção das notícias. Nos primórdios das pesquisas em Comunicação, Kurt Lewin já mencionava os gatekeepers para demonstrar como a organização interna de um jornal influenciava mais na produção da notícia que o público (WOLF, 2002, p. 187). A indefinição desse Outro deslocaria a função de interlocutor para aqueles que estão mais próximos, e que efetivamente leriam, comentariam e criticariam os textos produzidos. É ali, nas redações e nos corredores, que o prestígio do campo jornalístico se distribui, pois só ali ele é compreensível e possui valor. Para essas vertentes das teorias da comunicação, o público tem sua importância praticamente anulada em nome de aspectos inerentes à produção jornalística, pelo menos no que diz respeito à filtragem e seleção de notícias a serem publicadas: 
Sobre esse tema, as pesquisas coincidentemente esclarecem que, na seleção, as referências implícitas no grupo de colegas e no sistema das fontes prevalecem sobreas implícitas do próprio público. Enquanto este último é pouco conhecido pelos jornalistas, o contexto profissional-organizacionalburocrático circunstante exerce uma influência decisiva nas escolhas dos gatekeepers. (WOLF, 2002, p. 187)

Também Gomes (2004) ressalta como a formação de um campo jornalístico pressupõe, muitas vezes, a hierarquização das relações entre jornalistas e os outros representados pelos campos político ou econômico. Ao invés de lidar com o público, o jornalista se preocupa em lidar com o Governo, com as assessorias, com os anunciantes, ou seja, com as fontes de sustentação da empresa jornalística. Da mesma forma, retornando-se ao conceito de Leitor-Ideal, é possível sugerir que o texto jornalístico, texto fechado e fruto de uma rotina produtiva intensamente influenciada por valores mercadológicos, já propiciaria uma imagem estandartizada de público, retirando dos jornalistas a necessidade de pensar em para quem falariam ou escreveriam. Nesse caso, a produção jornalística seria entendida como um processo meramente mecânico, indiferente e não-subjetivo, quase como uma atividade industrial. Por fim, também é possível afirmar que as pesquisas de público, a aferição quantitativa ou qualitativa de audiência, e vários outros mecanismos científicos similares transfeririam a responsabilidade de definir quem é o público para os departamentos publicitários ou econômicos das empresas jornalísticas. Aos jornalistas caberia apenas alimentar a máquina de realidades com sua mão-de-obra produtiva.

Todos os aspectos acima citados convergem para a noção de que o público se tornou um personagem secundário e coadjuvante do fazer jornalístico. Em algumas circunstâncias, ele chega a ser considerado como desnecessário. Mas, sem entrar no mérito prático dessa questão, quando se trata de campo simbólico, as ordenações de hierarquia nem sempre condizem com o fazer cotidiano.

Em outras palavras, não se pode afirmar que apenas pelo fato do contexto de mercado transformar o jornalismo em uma atividade puramente mercadológica significa que, necessariamente, os jornalistas tenham abdicado de imagens idealistas de seu público. Essa visão do fazer jornalístico não deixa também de ser exatamente isso: uma visão, um ponto de vista. Um dos muitos construtos significativos que compõem o sistema simbólico do campo. De qualquer forma, a concepção de um jornalismo mercadológico, extremamente objetivo e economicista, também trabalha com imagens arquetípicas do próprio jornalista e do público. Traquina cita Roeh para demonstrar como essa recusa à subjetividade, esse desprezo quase 
visceral a qualquer ideia de um jornalismo idealista e grandiloquente, é uma das principais e paradoxais características da própria mitologia jornalística:

O fenômeno mais impressionante no jornalismo ocidental, tanto na práxis como na teoria, é a fé metafísica obstinada e conservadora de que a linguagem é transparente. Ou, de outra forma: o erro assenta na recusa dos jornalistas, mas também dos estudantes de jornalismo, em situar a profissão onde esta pertence, isto é, no contexto de expressão humana da atividade expressiva. É a recusa de lidar com a escrita das notícias por aquilo que é na essência - contar 'estórias' (ROEH, 1989 apud TRAQUINA, 2008, p. 18)

Portanto, o público como Outro deixa refletir em sua definição os mesmos dilemas que o campo jornalístico enfrenta em sua auto definição simbólica. Isso porque o jornalismo atual é um pensamento de uma época paradoxal - um período em que foram construídos, a partir da mesma origem, tanto os conceitos de democracia, de liberdade individual, de contestação política, quanto os conceitos de consumismo, de culto ao mercado, de hedonismo materialista, de existência espetacular. Um homem que tem o direito de escolher o que quer ser mas, ao mesmo tempo, tem o dever de consumir para ser o que quer que seja - direito de ser para ter, dever de ter para ser - eis o homem primordial que povoa os mitos fundadores do jornalismo. E é a partir dessa dualidade (que a sociedade capitalista tornou natural) que Traquina vai se referir aos polos "econômico" e "intelectual" do jornalismo, e toda a questão crucial do fazer jornalístico trará em si a marca da mesma dicotomia. No âmbito do simbólico, que é o que se procura aqui, o homem livre-consumidor, democrático-materialista, capitalista-ecológico, enfim, o homem que possui o direito e o dever de consumir, servirá de molde arquetípico para que o jornalista responda à pergunta: “quem é meu público?”.

Torna-se compreensível e até natural que a imagem do público, para o jornalista, transite com tanta facilidade entre o "público-cliente", que consome notícias como se comprasse bolachas e quer resultados imediatos, e o "público-cidadão", cioso da construção de uma sociedade mais justa e que tem o direito de saber e de se proteger contra as arbitrariedades do poder. Tal transitoriedade displicente também pode ser observada na compreensão que o jornalista tem de si mesmo: ele desloca-se com desenvoltura entre o “jornalista-funcionário", um operário das palavras e um produtor industrial de informação, e o “jornalista-resistente”, que levanta bandeiras e aponta as agruras da sociedade, convidando o público à reflexão ou à rebeldia, mantendo a cultura acesa num mundo caótico. 
Baluarte da justiça contra os opressores ou servidor braçal da informação, formador de opinião ou papagaio do poder, luz para os desvalidos sociais ou abutre da miséria humana, vigilante da moral ou do moralismo, instrumento da democracia ou do mercado, todas essas são acepções míticas do jornalista (por isso grandiloquentes). Elas habitam e compõem o espaço simbólico desse fazer profissional, seja na forma de aspirações nunca totalmente reveladas, ou de utopias mais ou menos assumidas, seja como confissões descrentes quanto ao próprio trabalho, ou como crítica ao próprio campo e à própria cultura jornalística. De uma forma ou de outra, elas pertencem ao imaginário que o campo produz e propõe.

Mas a cultura jornalística é também uma cultura rica em mitos, símbolos e representações sociais que fornecem a esta comunidade interpretativa toda uma liturgia de figuras bem claras dos vilões e dos heróis a que os membros da tribo prestam homenagem ou devotam ódio. O próprio 'ethos jornalístico' é determinante na elaboração de mitos (TRAQUINA, 2005, p. 51).

E é justamente a partir dessa autoafirmação que os jornalistas compreenderão e definirão seu público. O público é sempre um Outro que completa a lógica simbólica do $E u$ jornalístico. Se o jornalista é um fabricante de notícias, o público é o consumidor, se o jornalista é um ilusionista, o público é a plateia de circo, se o jornalista é um vendedor de atenções, o público é a matéria-prima, se o jornalista é o herói da democracia, o público é a mocinha indefesa nos trilhos do trem. E se o jornalista não leva o público em consideração, ou nunca realmente levou, para realizar seu trabalho - porque os interesses jornalísticos nem sempre são voltados par ao público, ou porque há Outros demais na relação jornalística, ou até porque a rotina produtiva tire dele a necessidade de pensar num público - isso não significa que o público não esteja ali em algum canto, espiando de longe, e esperando o momento em que o jornalista perguntará a si mesmo será que há alguém do outro lado? para saltar sobre ele como uma aparição fantasmagórica.

\section{AS IMAGENS DO PÚBLICO}

A pesquisa empreendida entrevistou jornalistas de dois jornais impressos goianienses - a ver, O Popular e Diário da Manhã - e de variadas editorias e funções jornalísticas. Considera-se necessário fazer algumas delimitações: em primeiro lugar, a pesquisa focou o jornalista e não o seu público, uma vez que seu objetivo não foi definir qual o leitor real das matérias jornalísticas, mas sim tentar captar a imagem que o jornalista tem desse leitor; em segundo lugar, o objeto de análise foi o discurso narrativo e oral do jornalista, obtido através

Comun. \& Inf., Goiânia, GO, v. 20, n. 2, p. 152-170, jul./out. 2017 
de entrevistas em profundidade, e não o texto jornalístico; e, finalmente, convém ressaltar que não foi intuito do pesquisador contrastar realidade com a imagem da realidade. Tinha-se consciência que o objeto da pesquisa é uma realidade do campo simbólico, e foi exatamente nesse campo que se realizou seu estudo.

A escolha do $O$ Popular e do Diário da Manhã se deveu à tradição que eles possuem na capital, bem como à sua relevância e acessibilidade. São as duas publicações diárias mais conhecidas da cidade e apresentam histórias distintas e posicionamentos ideológicos e funcionais por vezes antagônicos. Convém registrar que a maior parte dos jornalistas goianienses, inclusive os mais jovens, passou por mais de um veículo de comunicação em sua trajetória profissional. Outros veículos como O Hoje, o Tribuna de Goiás, Tribuna do Planalto etc., podem aparecer nos discursos colhidos. Foi também recorrente a realidade de que os entrevistados tenham trabalhado tanto no Diário da Manhã quanto no O Popular em algum momento de suas carreiras.

A pesquisa detectou que pelo menos 8 imagens de leitor se repetiram em mais de uma das entrevistas realizadas. Essas imagens foram nomeadas assim: leitor-fonte, leitor-médio do O Popular, leitor-sociedade, leitor-de-hoje, leitor-ao-lado, leitor-editor, leitor-de-impresso, e leitor-consumidor. As imagens de leitor detectadas nunca foram exatamente iguais em todas as entrevistas. Cada entrevistado apresentou um panorama muito particular da realidade. Mais do que a formulação racional e estruturada dos fatos, a metodologia utilizada favoreceu, através de perguntas abertas e incentivo à narrativa pessoal, a exposição de idiossincrasias e subjetividades. Considera-se que a pesquisa teve sucesso nesse ponto: os entrevistados contaram histórias, anedotas, expressaram opiniões pessoais, confidenciaram impressões, afirmaram paradoxos e se contradisseram, voltaram atrás, negociaram suas convicções dentro do próprio discurso, e etc. Ao final, cada entrevista se mostrou como um corpo unitário, dono de uma lógica interna própria, de uma problemática particular e reconhecível em relação aos outros.

Diante de um material dessa natureza, o esforço analítico proposto foi o de detectar padrões subentendidos nos discursos. As imagens de leitor aqui apresentadas são, portanto, inferências analíticas do pesquisador. Em geral, elas não apareceram já prontas nas entrevistas; foram, isso sim, construídas a partir da convergência de semelhanças, coincidências e tendências reconhecidas nesses discursos. Desse modo, as 8 imagens colhidas pela pesquisa representam generalizações que absorveram os posicionamentos pessoais de cada entrevistado. Em muitos momentos elas podem se confundir, se misturar ou chocar.

Comun. \& Inf., Goiânia, GO, v. 20, n. 2, p. 152-170, jul./out. 2017 
Mas, no geral, resumem apropriadamente os principais paradigmas, crenças e confrontos reconhecíveis nas entrevistas realizadas. O que se apresentará nesse artigo é apenas um resumo das imagens inferidas, sem o detalhamento da totalidade de características e de justificativas para cada uma:

1) O Leitor-Fonte: O Leitor-Fonte é um leitor com rosto, nome e voz. Ele apareceu na maioria das entrevistas como a representação dos vínculos profissionais e extraprofissionais entre os jornalistas e aquelas pessoas diretamente envolvidas nas matérias. Dentro desse quadro não estão apenas as fontes jornalísticas, mas os assessores de imprensa, parentes, amigos e todos aqueles cujo interesse na leitura das matérias é evidente para o jornalista.

É importante ainda perceber que o Leitor-Fonte não é constituído de indivíduos pertencentes à esfera profissional mais próxima do jornalista. Todos aqueles citados nas entrevistas pertencem a campos externos à redação.

2) O Leitor-médio do $\boldsymbol{O}$ Popular: O leitor-médio do $O$ Popular está pré-definido pela linha editorial da empresa jornalística. Ele é constituído pela parcela mais culta e bem-educada da população goianiense, com alto poder aquisitivo e boa capacidade analítica. Ela surge sempre na comparação entre públicos do $O$ Popular e do tabloide Daqui, da mesma empresa. O jornal Daqui é uma publicação declaradamente criada para o chamado "público C e D", enquanto $O$ Popular apregoa, em suas peças publicitárias, ser o jornal para uma população mais elitizada. Os entrevistados parecem perceber que se trata de uma divisão de cunho publicitáriocomercial. Interessante notar que não há, em nenhuma entrevista, formação de um LeitorMédio do Diário da Manhã. Infere-se que isso se deve ao fato, reiterado por vários entrevistados, de que o $O$ Popular seria uma empresa jornalística mais profissional e organizada que o Diário da Manhã, considerado como uma "empresa familiar".

3) O Leitor-sociedade: O Leitor-Sociedade é um leitor coletivo, ativo e participativo, membro de uma esfera pública de direitos e deveres bem definidos. Corresponderia a uma ideia muito ampla, muito abstrata, mas muito presente de sociedade democrática. Nesse caso, a ideia só existe a partir de um arcabouço de cunho político: é a sociedade oriunda do sistema democrático, absorvendo para si todos os símbolos positivos da democracia. Assim sendo, sempre que a imagem surge, ela está vinculada à questão das funções sociais do jornalismo. O Leitor-Sociedade existe a partir do momento em que existe a suposição de uma organização Comun. \& Inf., Goiânia, GO, v. 20, n. 2, p. 152-170, jul./out. 2017 
democrática dentro da qual tanto o jornalismo quanto a sociedade civil possuem funções específicas: o primeiro, de informar e vigiar os detentores do poder, e o segundo, de escolher seus líderes com prudência. O Leitor-Sociedade, portanto, seria um tributário da concepção do jornalista como fiscalizador social, combativo e politicamente ativo. No fundo, ele funciona como uma justificativa para essa imagem de jornalismo.

4) O Leitor-de-hoje: A imagem do Leitor-de-hoje é uma das mais interessantes encontradas pela pesquisa. É perceptível a ligação entre o Leitor-de-hoje e a imagem que os entrevistados fazem do "mundo atual", do "nosso tempo", ou da "nossa sociedade". Todas as entrevistas vincularam o Leitor-de-hoje ao seguinte triângulo de sentido: no vértice, encontra-se a tecnologia, os avanços da comunicação, a rapidez da informação; na base está, de um lado, a maior exigência, maior cultura e maior velocidade, e do outro, a menor exigência, maior desatenção e busca apenas pelo superficial. Em outras palavras, o Leitor-de-hoje tem sempre a ver com os avanços tecnológicos e comunicacionais, mas pode tender para um lado positivo - de leitor mais consciente e crítico - ou negativo - de leitor mais fútil e desatento.

5) O Leitor-ao-lado: O Leitor-ao-lado é visto com muito carinho e consideração. Ele é a pessoa normal, o "cidadão comum”, que passa na mesma rua que o jornalista, que compra pão na mesma padaria, e que gostaria de ver seus problemas transformados em notícia. Durante a pesquisa, os entrevistados mencionaram o Leitor-ao-lado sempre que houve possibilidade de expressar um tipo de idealismo específico: o desejo de entender o jornalismo como contar histórias. O Leitor-ao-lado seria, portanto, o vizinho, a pessoa comum com quem o jornalista trava contato, e de onde ele deve retirar a matéria-prima para sua produção. Mas o Leitor-aolado deixa transparecer uma característica mais sutil: ele é incapaz de enxergar a riqueza de seu próprio cotidiano. Ou, pelo menos, incapaz de expressá-la, seja por não ter os meios, seja por não ter a técnica. Nesse ponto, a afetividade adquire certos matizes de superioridade. Não se trata de uma superioridade manifesta e nem depreciativa. É, na verdade, uma delimitação simbólica de fronteiras. O jornalista está próximo do Leitor-ao-lado, tanto que o entende e o preza, mas ele não é o Leitor-ao-lado. Os olhos do jornalista enxergam mais profundamente, mais poeticamente, ele é capaz de entender mais, e por isso é jornalista.

6) O Leitor-editor: Em tese, ele seria um leitor real, presente e definível: os editores dos jornais, pessoas com as quais os jornalistas convivem diariamente, e pelas quais nutrem Comun. \& Inf., Goiânia, GO, v. 20, n. 2, p. 152-170, jul./out. 2017 
relações tanto profissionais quanto pessoais. A tendência natural seria a de que os jornalistas reconhecessem nos editores os primeiros leitores das matérias. Afinal, eles realmente as leem, e seu feedback é imediato, face-a-face. Escreve-se para o chefe, para o colega jornalista, para o editor. Contudo, a pesquisa averiguou que haveria uma concepção generalista e abstrata na figura do Leitor-Editor. Constatou-se que, na maioria dos casos, o Leitor-editor não representa apenas os indivíduos que exercem o cargo de editoria no jornal, mas a própria linha-editorial desse jornal. O uso do pronome "eles" para definir os editores do jornal foi recorrente. Não se trata de fulano ou sicrano, editor de esportes ou de economia, mas "deles", dos editores do jornal. O Leitor-Editor, portanto, não representa exatamente os indivíduos no cargo de editoria. Ele é mais uma composição abstrata que regula e regulamenta o texto jornalístico, cobrando certos valores e mantendo a linha editorial.

7) O Leitor-de-impresso: Nas entrevistas, o leitor-de-impresso apresenta-se como uma figura positiva, um tanto heroica, um tanto trágica. Ele procura o impresso mesmo tendo acesso a outras mídias consideradas mais atuais ou efetivas. É, portanto, um leitor ativo, e capaz de escolher por própria conta o que quer. O leitor-de-impresso lê jornal porque espera encontrar ali a reflexão e a credibilidade que não se acha na televisão, no rádio ou na internet.

8) O Leitor-consumidor: Todos os entrevistados confessaram a existência de um leitor que sustenta financeiramente o jornal e que não se importa com os dilemas éticos do fazer jornalístico. O verbo "confessar" parece ser o mais adequado para o caso; a existência de um leitor assim depõe contra toda luta por um jornalismo melhor e mais edificante. Ele foge das tentativas nobres de imaginar uma sociedade ativa, um leitor cidadão, que compensasse ou justificasse um jornalismo também ativo e cidadão. O leitor-consumidor escapa entre os dedos do jornalista, não por ser esperto ou sagaz, mas exatamente pelo contrário: ele é simplório, instintivo, imediatista. Real como um grande monólito, o leitor-consumidor prostra-se diante do sonho jornalístico e exige espetáculo, violência, futilidade. Ele é o leitor aferido pelas estatísticas da empresa. Seu feedback é dado em números de venda, de acessos ou de assinaturas. Esses foram considerados indícios da existência de um leitor massivo e voraz, que não funciona como indivíduo, mas como uma espécie de força magnética: certas matérias, temáticas e abordagens o atraem violentamente, enquanto outras o rechaçam. Ele materializa o momento em que o jornalismo perde seu caráter de "seriedade", de arauto dos fatos, e se entrega a interesses menos nobres. Essa mudança de estado é vista, nalgumas 
entrevistas, com desprezo e, noutras, como uma atitude inevitável. Para todo efeito, o terceiro aspecto é de que o leitor-consumidor é algo real e está aí, no mundo. O jornalista o constata como realidade e deve lidar com isso, tolerando-a, compreendendo-a, ignorando-a.

\section{ALGUMAS CONSIDERAÇÕES FINAIS}

Ao final do trabalho, considera-se que o objeto transcendeu a pesquisa, que a realidade suplantou a hipótese, e isso só pode resultar em estímulos para que o estudo continue no futuro. As inferências que compuseram esse trabalho não se pretendem conclusivas, mas sugerem um campo interessante de pensamento e questionamento em Comunicação.

As imagens de leitor podem ser consideradas estereótipos por simplificarem a condição complexa e desconfortável de uma mensagem destinada a "qualquer pessoa". Constituem uma redução do abstrato ao palpável quando, por exemplo, se personificam nas fontes, nos editores, ou nos leitores que escrevem cartas, telefonam ou comentam virtualmente as notícias. Mas o mais intrigante está na relação dessas imagens com entidades muito amplas e sem feedback objetivo, direto, reconhecível. Nesses casos, os estereótipos deixam resvalar suas intenções basilares, e se revelam como o que verdadeiramente são: mecanismos de legitimação da realidade construída por quem os defende.

A experiência com a imagem dos leitores parece ser, dentro desse prisma, um campo de observação privilegiado, que se aproxima das definições de Lippmann sobre os estereótipos e, principalmente, do estudo de Tyteca-Perelman (2005) sobre o auditório universal. O leitor do jornal - o grande público-leitor, aquele "para quem se escreve"- nunca responderá diretamente as mensagens, isso porque ele é muito mais uma ideia ampla do que um ente concreto. Por isso, ele se torna o ator coadjuvante perfeito, o receptáculo ideal no qual está depositada as imagens de "para quem se gostaria de escrever" ou "para quem se é forçado a escrever". Nele o jornalista encontra espaço para enfrentar suas crises de identidade, suas demarcações de território. Nele o jornalista deposita as justificativas para seus atos, e os discursos que corroboram sua visão de mundo, como um ventríloquo convencido de que seu boneco está vivo.

De modo que, na verdade, parece que os jornalistas encontraram uma solução bastante sutil para lidar com o peso do abstrato, do múltiplo, do caos de um público infinito: de forma quase inconsciente, eles diluíram a pergunta pragmática "para quem escrevo?" dentro da questão conceitual "por que escrevo?". Ao deixar de escrever "para alguém", e passar a escrever "por um motivo", os jornalistas não perdem de vista a imagem de um público-leitor,

Comun. \& Inf., Goiânia, GO, v. 20, n. 2, p. 152-170, jul./out. 2017 
mas a subjugam, a subsumem, transformando-a num eixo secundário de todo o arcabouço simbólico vinculado a um ideal teleológico de profissão. Em outras palavras, existe um objetivo maior, uma meta final em ser jornalista - o público-leitor, contudo, não seria essa meta.

As linhas demarcatórias de uma identidade jornalística foram detectadas, mas com graus de flexibilidade e subjetividade muito maiores do que o esperado. Isso pode indicar que um campo social do jornalismo exista mais como uma realidade idealizada do que efetiva. É provável que tal fato tenha algo a ver com o contexto histórico e social dos objetos estudados. O Popular e o Diário da Manhã são jornais relativamente jovens, dentro de uma estrutura social também muito recente. Segundo os conceitos defendidos por Gomes (2004), pode ser que o contexto atual de Goiás não facilite o desenvolvimento de um campo social do jornalismo. Há ainda práticas políticas muito arraigadas no ambiente empresarial do Estado. Elas se condensam e se manifestam em uma forte cultura de favores e apadrinhamentos, de priorização dos sobrenomes aos nomes, e de uma percepção ainda bastante simplificada do mercado e das culturas profissionais. Tais circunstâncias não forneceriam aos jornalistas a autonomia necessária para, de acordo com Gomes (2004), se constituir em um campo social próprio.

Já Bourdieu e Traquina se preocupam mais com a abrangência do campo econômico sobre o jornalismo. Traquina (2008) faz referência aos polos "econômico" e "intelectual" que compõem o campo e geram tensões de identidade entre seus componentes. De fato, a pesquisa demonstrou como os jornalistas se resguardam de uma imagem puramente mercadológica através da manutenção de certa aura intelectual e social. A função social do jornalismo - que, no fundo, é uma noção política calcada na ideia de democracia - surge como opção superior ao simples utilitarismo de mercado. Já a intelectualidade, ainda que poucas vezes defendida abertamente, constrói barreiras sutis entre o campo jornalístico e o senso-comum. Todos esses elementos convivem no interior da identidade jornalística, enquanto os profissionais transitam entre eles a depender da circunstância. São "operários" quando querem enfatizar a pressão maçante das rotinas produtivas de um jornal; são "a voz do povo" contra os desmandos dos poderes instituídos; são a "reserva de cultura e cidadania" contra a massa ignóbil.

A leitura feita de Bourdieu e Traquina para esse trabalho pode sugerir que essas áreas movediças sejam as fronteiras de um campo que procura sua identidade. Os resultados da pesquisa, porém, permitem outra sugestão: talvez a crise não seja de identidade, mas de posicionamento. E mais: será que a crise não seria uma característica natural da identidade

Comun. \& Inf., Goiânia, GO, v. 20, n. 2, p. 152-170, jul./out. 2017 
jornalística? Uma identidade que nasceu ao mesmo tempo do mercado e da intelectualidade, da democracia e do poder, e que se construiu tanto sob a égide da intermediação, do meio-decampo, quanto sob a bandeira da defesa de direitos, da luta contra os poderosos. Grande parte da mitologia jornalística simplesmente deixaria de existir caso não houvesse inimigos, conspirações e traições. Em uma das entrevistas realizadas, um jornalista afirma algo esclarecedor, e que vale a pena ser citado:

No fundo, no fundo, é sempre um problema público. Independente do que aconteça, é sempre um problema público. No fundo, sempre vai acontecer alguma coisa porque algum agente público não fez o que deveria ter feito. Se teve um acidente, é porque não tá a fiscalização das pessoas que tão andando ali acima da velocidade. (...) Se teve um buraco na rua, é culpa deles. Se as pessoas tão morrendo nos hospitais porque não tem leito, é culpa deles.(...) $\mathrm{O}$ que era até complicado, porque chegou um momento que a gente não podia falar mal do governo, porque o governo tinha pagado anúncio pro jornal, então não podia falar mal do governo. Então, passado um tempo,ele queria tirar anúncio também da prefeitura, ele falou: vamos segurar um pouco da prefeitura, não pode falar mal da prefeitura não. Vamos falar mal de quem então? (risos) Não pode falar mal da prefeitura, não pode falar mal do governo, não pode falar mal de nada! Vamos fazer matéria de quê? De que a dona Maria lá ganhou um cachorro? Só essas coisas? (Entrevista 2 em UMBELINO FILHO, 2013, p. 108)

A luta contra o poder instituído fica evidente como um valor simbólico para o entrevistado. Reconhecer os problemas públicos seria a razão de existir do jornalista. Mas, mais que isso, o que se pode aferir desse e de outros trechos, é a exigência axiomática de uma postura crítica. Não apenas no fazer jornalístico, na condução profissional e na confecção da notícia, mas também no relacionar-se com outros campos sociais, e no pensar o mundo e a si mesmo. O jornalismo seria uma profissão crítica por excelência.

Uma das expectativas principais do pesquisador era encontrar a imagem de um leitorcidadão. Isso porque a mídia faz largo uso da palavra cidadania em seu discurso. Trata-se, de fato, de um conceito que caiu muito bem ao gosto do chamado "grande público" e que, na boca dos grupos sociais, gera variados tipos de abordagem - de conceito científico a dogma político, de bandeira de campanha a componente de valoração ética, de baluarte ideológico a estratégia publicitária, de elemento de mitologia popular a moeda de troca. E é a mídia que, encastelada em seu nicho de especialista na construção de valores simbólicos, parece propagar com maior ênfase a questão da cidadania. Mas, curiosamente, a imagem de um leitor-cidadão praticamente não apareceu. 
A inferência final desse trabalho é que os jornalistas teriam certa dificuldade de trabalhar com um conceito de cidadão ativo e consciente. A imagem do leitor, mesmo quando apresentada em suas melhores vertentes, ainda assim carregava traço fortes de passividade. Como se a cidadania, e qualquer outro conceito enobrecedor da função jornalística, fosse um bem em posse dos jornalistas - algo a ser outorgado, dividido, ensinado aos demais. Ao invés de falar a cidadãos, os jornalistas falariam "para cidadanizar".

Falar a cidadãos é muito diferente de falar para "cidadanizar". No primeiro caso realiza-se, no próprio ato da fala, um exercício de cidadania; falar a cidadãos é ser também cidadão, e exercer direitos e deveres - é saber a justa medida do outro e de si mesmo no processo de construção da consciência. O segundo caso é catequese. Pois só se "cidadaniza" aquele que não é cidadão - o bárbaro, o incapaz, a vítima vulnerável e passiva. Talvez essa expressão "cidadanizar" soe tão estranha, tão feia, por guardar em si uma incongruência: ora, se a cidadania é a construção da própria consciência em uma sociedade formada por indivíduos ativos, livres e pensantes, como seria possível cidadanizar alguém? Como impor a cidadania? Enfim, falar a cidadãos é diferente de falar para cidadanizar do mesmo modo que escrever "para alguém" é diferente de escrever "por um motivo".

Nunca foi objetivo desse trabalho solucionar um aspecto tão complexo quanto a relação jornalista-público. Há um número incontável de vertentes, de objeções, de pontos de vista, que poderiam contradizer ou por abaixo tudo o que foi dito aqui. Mas ao final da pesquisa, parecem legítimas certas inquietações do pesquisador, e sincera a vontade de aprofundar no estudo desses pontos. Tão importante quanto estudar os efeitos, os resultados, as implicações de nossas ações como jornalistas, como comunicadores, como pesquisadores, seria também procurar as causas - estudar nosso próprio olhar, nossos próprios mitos e a forma como enxergamos o Outro. É possível que só assim conseguiremos, de fato, encarar o mundo sem nos assustarmos com tudo aquilo que não é espelho.

\section{REFERÊNCIAS BIBLIOGRÁFICAS}

BOURDIEU, Pierre. O Poder simbólico; tradução Fernando Tomaz 12a ed. Rio de Janeiro; Bertrand Brasil, 2009.

GOMES, Wilson. Transformações da política na era da comunicação de massa. São Paulo: Paulus, 2004.

LIPPMANN, Walter. Opinião Pública. 2a ed. - Petrópolis, RJ: Vozes, 2010. 
LUHMANN, Niklas. A realidade dos meios de comunicação. São Paulo: Paulus, 2005

MAFFESOLI, Michel. O tempo das tribos: o declínio do individualismo nas sociedades pós-moderna $-4^{\mathrm{a}}$ ed. - Rio de Janeiro: Forense Universitária, 2006.

PERELMAN, Chaïm; TYTECA, LucieOlbrechts. Tratado de Argumentação. $2^{\mathrm{a}}$ ed. - São Paulo: Martins Fontes, 2005.

TRAQUINA, Nelson. Teorias do Jornalismo. A tribo jornalística - uma comunidade interpetativa transnacional. Florianópolis: Insular, $2^{\mathrm{a}}$ Ed. 2008.

WEBER, Max. Metodologia das Ciências Sociais, Parte 1. $4^{\text {a }}$ edição, São Paulo: Editora da Unicamp, 1993

WOLF, Mauro. Teoria da Comunicação de Massa $-7^{\mathrm{a}}$ ed. Barcarena, Portugal, Editorial Presença, 2002. 